\title{
Adhesion and transcellular migration of neutrophils and B lymphocytes on fibroblasts
}

\author{
Patrick Couture, Jérémie Paradis-Massie, Nadia Oualha-Morin, Gaétan Thibault
}

Institut de recherches cliniques de Montréal, Université de Montréal, Montréal, Québec, Canada

Address correspondence to:

Gaétan Thibault, PhD,

Institut de recherches cliniques de Montréal,

110, avenue des Pins ouest,

Montréal, Québec, Canada,

H2W 1R7

Tel: (514) 987-5613

Fax: (514) 987-5585

E-mail: thibaug@ircm.qc.ca 


\begin{abstract}
During tissue inflammation, infiltrated leukocytes may have physical contacts with fibroblasts. We observed that neutrophils and B lymphocytes adhered in a larger proportion than $\mathrm{T}$ cells on cultured fibroblasts. Microscopy showed that adhesion was also characterized by leukocyte engulfment by the fibroblasts. In migration assays, only neutrophils and B lymphocytes were selectively able to migrate through a fibroblast barrier. Adhesion and migration were increased by stimulation with tumor necrosis factor- $\alpha$ (TNF- $\alpha)$ and phorbol-12-myristate-13-acetate (PMA). Antibodies against ICAM-1/ß2 integrin blocked the interaction of neutrophils to fibroblasts. For B lymphocytes the couple VCAM-1/a4 integrin was also involved in this interaction. Human skin fibroblasts presented similar adhesion characteristics as rat cardiac fibroblasts. By measuring the distance between the border of migration holes and cadherinpositive adherens junctions, more than $65 \%$ of the holes correspond to the transcellular route over the paracellular route. Furthermore, vimentin staining revealed that the migration holes were highly nested by intermediate filaments in accordance with the transcellular route. Our results demonstrated that engulfment of neutrophils and B lymphocytes by fibroblasts resulted in selective passage by a transcellular route.
\end{abstract}

Keywords: Cell trafficking, emperipolesis, B cells, neutrophils, adhesion molecules, fibroblasts 


\section{Introduction}

During tissue inflammation, which is often an important outcome in several cardiovascular pathologies, leukocytes are attracted by chemokines and cross the vessel walls by relatively wellknown mechanisms. Surface receptors on endothelial cells and counter-receptors on leukocytes regulate a well-orchestrated dance. This machinery gradually attracts, stops and allows inflammatory cells to penetrate the endothelial layer by the paracellular and transcellular routes [1]. Once infiltrated, the leukocytes move inside connective tissues to encounter the source of the chemoattractants. Finally, via their own functions, they clean the injured tissues with consequent local remodeling.

Heart volume is at $70 \%$ composed of cardiac myocytes, but these cells only represent $30 \%$ of cell number. Other cell types correspond to endothelial, vascular smooth muscle, and nerve cells as well as fibroblasts. Cardiac fibroblasts are at the central pole of the ischemic area. Their ability to proliferate, differentiate into myofibroblasts and replace myocytes undergoing necrosis and/or apoptosis allows them to fill the empty space with fibrotic material [2]. The literature indicates that fibroblast metabolism and differentiation are influenced by several cytokines that originate from leukocytes [3,4], resulting in the formation of granulation tissue with the deposition of extracellular matrix proteins.

Put together, these two pieces of information suggest that the infiltrated leucocytes perceive the fibroblasts inside the connective tissue of the infarcted myocardium or in other tissues. It is likely that leukocytes interact directly with cardiac fibroblasts. Indeed, there are several examples in the literature of interactions between leukocytes and fibroblasts of different origins [5-15]. These interactions appear to modulate the level of subsequent fibrosis and might also affect the degree of inflammation in those tissues. For instance, it's well documented that, 
during the first hours after myocardial infarction, a massive leukocyte infiltration plays a crucial role in tissue remodeling [16]. The study of the fibroblast-leukocyte interactions and their modulation may bring new insights into the understanding and the possible interventions in inflammation after tissue injury.

In the present study, we investigated the interaction between leukocytes and fibroblasts and took it a step further. We demonstrated that fibroblasts can engulf leukocytes, acting, thus, as selective filters that allow only the migration of neutrophils and B lymphocytes via a transcellular route. 
Materials and methods

\section{Antibodies and reagents}

Antibodies against CD18 (clone WT.3), CD11a (clone WT.1), CD11b (clone OX-42), CD11c (clone 8A2), CD49d (clone TA-2), ICAM-1 (clone 1A29), VCAM-1 (clone 5F10), granulocytes (clone RK-4), CD45RA (clone OX-33), CD4 (clone W3/25), CD5 (clone OX-19), CD8a (clone OX-8), $\alpha$-tubulin (clone DM1A), vimentin (clone V9), and pan-cadherin (clone CH-19) were purchased from Cedarlane Laboratories (Hornby, ON), AbD Serotec (Raleigh, NC), Millipore/Chemicon (Billerica, MA), Covance (Berkely, CA) or Sigma-Aldrich (Saint Louis, MO). CellTrace Far Red DDAO-SE, CellTrace Oregon Green, TO-PRO-3, and secondary antibodies (AlexaFluor 488, rhodamine, PE) were bought from Invitrogen/Molecular Probes (Eugene, OR). TRITC-phalloidin was from Sigma-Aldrich.

\section{Cell cultures}

Animal housing and experimentation in accordance with Canadian Council on Animal Care and NIH guidelines were approved by the local animal care committee. Male Sprague-Dawley rats (200-250 g) were used in all experiments. Primary cultures of cardiac fibroblasts were obtained by trypsin digestion of rat hearts as described previously $[17,18]$. The cells were grown in lowglucose Dulbecco's minimal essential medium (DMEM), $0.2 \%$ bovine serum albumin, $10 \%$ fetal bovine serum and antibiotics. They were studied between passages 1 to 4 . Cultured cardiac fibroblasts have purity greater than $95 \%$ as evaluated with specific markers (vimentin, thy-1, and $\alpha 8$ integrin). Human skin fibroblasts were obtained from Dr. J. Genest Jr. (McGill University, Montreal, QC). 


\section{Isolation of rat granulocytes, mononuclear cells and B lymphocytes}

Granulocytes and PBMC were isolated from the peripheral blood of rats anesthetized with ketamine and xylazine. Briefly, blood was collected from the abdominal aorta in the presence of 2.7 mM EDTA. An isoosmotic Percoll cushion enabled the separation of granulocytes from PBMC by centrifuging the leukocytes [19]. Then, erythrocytes were removed from the granulocyte fraction by lysis with $\mathrm{NH}_{4} \mathrm{Cl}$. B lymphocytes were isolated from $\mathrm{PBMC}$ on an autoMACS cell separator (Miltenyi Biotec, Auburn, CA) by positive selection with OX-33 (CD45RA) antibody coupled with magnetic beads. In the rat, this antibody is specific to B cells [20]. Neutrophils (RK-4 $\left.4^{+}\right)$, B lymphocytes $\left(\mathrm{CD}^{2} 5 \mathrm{RA}^{+}\right), \mathrm{T}$ helper lymphocytes $\left(\mathrm{CD}^{+} \mathrm{CD} 4^{+}\right), \mathrm{T}$ cytotoxic lymphocytes $\left(\mathrm{CD}^{+} \mathrm{CD} 8^{+}\right)$, and $\mathrm{NK}$ cells $\left(\mathrm{CD} 5^{-} \mathrm{CD} 8^{+}\right)$were identified by flow cytometry $[21,22]$. Granulocyte and B lymphocyte purity exceeded $85 \%$.

\section{Assessment of leukocyte-fibroblast interaction by flow cytometry}

Interactions between leukocytes and fibroblasts were examined by flow cytometry after loading the cells with fluorescent probes. The fibroblasts were incubated for $30 \mathrm{~min}$ with $1 \mu \mathrm{M}$ CellTrace Far Red DDAO-SE. Granulocytes or PBMC were loaded with $1 \mu \mathrm{M}$ CellTrace Oregon Green. Cultured fibroblasts $\left(5 \times 10^{4}\right)$, harvested by trypsinization, were incubated at room temperature for 1 hour with either granulocytes or PBMC $\left(2 \times 10^{5}\right)$ at a ratio of 4:1 leukocytes/fibroblast in $100 \mu \mathrm{L}$ of DMEM plus $2 \%$ calf serum. At the end of incubation, $100 \mu \mathrm{L}$ of $4 \%$ paraformaldehyde in phosphate buffered saline (PBS) were added to each tube. The cells were analyzed on a Cyan flow cytometer (Dako, Carpinteria, CA). DDAO-positivity $\left(\mathrm{DDAO}^{+}\right)$and Oregon Green-positivity $\left(\mathrm{OG}^{+}\right)$(upper right quadrant) represented interacting cells. The results were expressed as percentages of fibroblasts that were $\mathrm{DDAO}^{+} / \mathrm{OG}^{+}$when gated on the total 
fibroblast population in forward scatter/side scatter plots. To further examine the interacting cells, $\mathrm{DDAO}^{+} \mathrm{OG}^{+}$cells were isolated in a MoFlo cell sorter (Dako). $\mathrm{DDAO}^{+} \mathrm{OG}^{+}$cells were then fixed and spun in a Shandon Cytospin 3 centrifuge (Thermo Scientific, Pittsburgh, PA) on Superfrost/Plus glass slides.

\section{Leukocyte transmigration}

Migration of leukocytes on fibroblast layers was assessed quantitatively in modified $0.33-\mathrm{cm}^{2}$ Boyden chamber with 3- $\mu$ m pore size filters (Becton Deckinson Labware, Franklin Lakes, NJ). Fibroblasts $\left(1 \times 10^{5}\right.$ cells $\left./ 0.33 \mathrm{~cm}^{2}\right)$, seeded on fibronectin-coated filters and grown for 2 days in complete DMEM to reach confluence, were starved overnight in serum-free DMEM, then stimulated for 24 hour with $30 \mathrm{ng} / \mathrm{mL}$ TNF- $\alpha .6 \times 10^{5}$ leukocytes, pre-loaded with $1 \mu \mathrm{M}$ CellTrace Oregon Green, were applied at the top of the inserts. A chemoattractant was then added to the lower well. After 6-h migration, leukocytes in the lower wells and under the filters were collected by centrifugation and solubilized with $2 \%$ sodium dodecyl sulphate in PBS. Fluorescence intensity was measured in a PHERAstar plus spectrofluorometer (BMG Labtech Inc., Durham, NC), and the number of migrated cells was evaluated by comparison with a standard curve. For qualitative assays, $2 \times 10^{6}$ leukocytes were applied to $1.12-\mathrm{cm}^{2}$ cell inserts. After 2-hour of migration, with or without chemoattractant, leukocytes in the upper and lower chambers were collected by centrifugation. They were then incubated with appropriate antibodies and analyzed by flow cytometry.

The integrity of the fibroblast layer was verified by adding ${ }^{125}$ I-albumin in the insert and measuring the amount of radioactivity crossing the layer. After $1 \mathrm{~h}$, we found that about $4 \%$ of

${ }^{125} \mathrm{I}$-albumin was present in the lower well. This data is comparable to that reported by Morzycki 
and Issekutz [23].

\section{Confocal and electron microscopy}

Fibroblasts were grown in fibronectin-coated Lab-Tek chambers (Nalge Nunc International, Rochester, NY) until confluence. Leukocytes $\left(3.3 \times 10^{5}\right.$ cells $\left./ \mathrm{cm}^{2}\right)$ were added on the fibroblast monolayers, then sedimented at low speed $(900 \mathrm{rpm})$ for $2 \mathrm{~min}$ and incubated at $37^{\circ} \mathrm{C}$. At the end of the 45-minute incubation, the wells were completely filled with medium, sealed with aluminum tape, inverted and centrifuged at low speed for 2 minutes. The cells were then fixed with 4\% paraformaldehyde in PBS. Depending on the experiments, the fibroblasts were preloaded with CellTrace Oregon Green and leukocytes with CellTrace Far Red DDAO-SE. Alternatively, fixed cells were stained immunocytochemically to detect myofilaments with TRITC-phalloidin, microtubules with anti- $\alpha$-tubulin, intermediate filaments with anti-vimentin. Fibroblasts express N-cadherin [24] and intercellular adherens junctions were revealed with a pan-cadherin antibody. An appropriate colored secondary antibody was chosen, depending or not whether the cells were loaded with an intracellular fluorescent tracer. Fluorescent images were obtained on a Zeiss laser confocal microscope (Axiovert 100M) with the Lasersharp software LSM 510 (Carl Zeiss Inc., Göttingen, Germany). For electron microscopy, MoFlo-isolated $\mathrm{DDAO}^{+} / \mathrm{OG}^{+}$cells were pelleted by centrifugation, fixed with $2.5 \%$ glutaraldehyde, post-fixed with $1 \%$ osmium, stained in $1 \%$ uranyl acetate, embedded in Durcupan, and post-stained in lead. They were examined in 50-nm thick slices with a JEOL JEM-1200EX transmission electron microscope (JEOL Ltd., Tokyo, Japan). 


\section{Statistical analysis}

The data were expressed as means \pm s.d.. Each experiment was repeated 3 times, and representative results are shown. All values were subjected to Student's t-test or 1-way ANOVA, followed by the Bonferroni t-test. $\mathrm{P} \leq 0.05$ values were considered to be significant. 


\section{Results}

\section{Leukocyte adhesion to fibroblasts}

When total isolated leukocytes were applied on cardiac fibroblasts grown in cell culture plates, we observed that they adhere to the cell monolayer after the removal of free cells. Adhesion was time-dependent, being maximal at 45 minutes, and saturable with about $2.5 \times 10^{4}$ leukocytes $/ \mathrm{mm}^{2}$. To determine which leukocyte types interact with fibroblasts, unbound and bound (EGTA-eluted) leukocytes were collected and analyzed by flow cytometry with appropriate cell-specific antibodies. Compared to the initial total leukocyte population applied on the fibroblasts which contained a large proportion of $\mathrm{T}$ cells $\left(\mathrm{CD}^{+} \mathrm{CD}^{+}\right.$and $\left.\mathrm{CD} 5^{+} \mathrm{CD} 8^{+}\right)$, EGTA-eluted bound leukocytes were clearly enriched in granulocytes (RK-4 $\left.{ }^{+}\right)$, B lymphocytes $\left(\mathrm{CD}^{2} 5 \mathrm{RA}^{+}\right)$, and NK cells $\left(\mathrm{CD}^{-} \mathrm{CD} 8^{+}\right)$(Fig. 1A). T cells were also bound to fibroblasts, but their proportions were significantly decreased, indicating that these leukocyte types were also attached, but more loosely.

We then undertook confocal microscopy to examine the appearance of adhered leukocytes on top of the fibroblast layers. For visualization, fibroblasts were pre-loaded with an intracellular fluorescent probe, CellTrace Oregon Green, and Percoll-isolated granulocytes and peripheral blood mononuclear cells (PBMC) with CellTrace Far Red DDAO. As seen in Fig. 1B to G, several PBMC or granulocytes adhered at the surface (white arrows), but others seemed to be more or less embedded in the fibroblast body (red arrows) with appearance of holes in the cytoplasm. In the experimental protocol, leukocytes were initially sedimented on the fibroblast layer by low-speed centrifugation to obtain rapid and close contact between the cells. Fibroblast embossing did not seem to represent leukocyte footprints, because only a small proportion of leukocytes showed this pattern. In addition, at higher field magnification, a 3-dimensional view 
(Fig. 1H) reveals that PBMC appeared to be completely inserted into the fibroblast cytoplasm. When the leukocyte reached the fibronectin-coated slides, they attached to the matrix and adopted a flatten appearance. It can also be appreciated that the fibroblast cytoplasm has begun to cover the leukocyte (white arrow heads). Similar pictures were observed for granulocytes (results not reported).

To further understand the phenomenon of leukocyte insertion into fibroblasts, flow cytometry was performed to identify cells that interacted together. Preliminary experiments showed that standard adhesion assays, in which fibroblasts were grown in 96-well culture plates, produced less reliable results because of false estimate of fibroblast number. Fibroblasts and leukocytes, at ratio of 4:1, providing an optimal response, pre-labeled with CellTrace Far Red DDAO and Cell Trace Oregon Green, respectively, were thus incubated together in suspension. In addition, incubations were conducted at room temperature, for a better preservation of cell integrity. After incubation and fixation, the cells were analyzed by flow cytometry. As illustrated in Fig. 2A, apart from the 2 original cell populations, a third population, which was positive for both fluorescent tracers $\left(\mathrm{DDAO}^{+} / \mathrm{OG}^{+}\right)$, was detected. This population was isolated with the MoFlo cell sorter and examined by confocal microscopy (Fig. 2B, C, and D). Although some leukocytes and fibroblasts were found to be isolated, probably due to the stress of sorter flow and collection, many leukocytes were still closely associated and clearly embedded in the fibroblasts. A 3-dimensional view, at higher magnification, clearly showed a leukocyte almost completely engulfed in them (Fig. 2E). Further examination of leukocyte-fibroblast interactions by electron microscopy (Fig. 2F and G) also demonstrated the complete inclusion of granulocytes or PBMC by fibroblasts.

To investigate if these interactions could be modulated by inflammatory agents, 
fibroblasts were stimulated with $10 \mathrm{ng} / \mathrm{mL}$ TNF- $\alpha$, and leukocytes were activated with $10^{-8} \mathrm{M}$ PMA. After fluorescent tracer loading and incubation, the cells were analyzed by flow cytometry (Fig. 3A). When gated on total fibroblasts, the proportion that became positive for Oregon Green, in the upper right quadrant, increased significantly with PMA and TNF- $\alpha$. Stimulation with both agents produced additive effects. Similar outcomes were observed when incubating fibroblasts with either granulocytes or PBMC (Fig. 3B). Stimulation of granulocytes with $10^{-8} \mathrm{M}$ fMLP also resulted in increased binding (results not shown).

To determine whether or not the observed adhesion and engulfment of leukocytes were specific to cardiac fibroblasts, the interactions were also examined with human skin fibroblasts. Fig. 3C illustrates that human skin fibroblasts were able to interact with leukocytes, and this interaction too was modulated by the same agents. Confocal microscopy of the $\mathrm{DDAO}^{+} / \mathrm{OG}^{+}$ cells also revealed the presence of leukocytes engulfed by skin fibroblasts (results not shown).

\section{Transmigration of neutrophils and B lymphocytes on fibroblast barriers}

To further understand the cellular significance of leukocyte internalization by fibroblasts, transmigration assays were performed. A layer of cardiac fibroblasts was grown on cell culture inserts with 3- $\mu \mathrm{m}$ pore size, and fluorescently-labeled leukocytes (PBMC, B lymphocytes, granulocytes, or total leukocytes) were deposited in the inserts. Leukocytes that transmigrated were collected and quantified by spectrofluorometry in comparison to a standard curve. Experiments demonstrated that the passage of leukocytes was time- and number-dependent (Fig. 4A and B). A 6-hour migration period in the presence of $6 \times 10^{5}$ leukocytes/well was considered to be optimal and between 1 to $4 \%$ of the leukocytes were collected. The chemoattractant fMLP increased and maximized the transmigration of granulocytes at a concentration of $10^{-8} \mathrm{M}$ (Fig. 
4C). Also, stromal cell-derived factor- $1 \alpha(\mathrm{SDF}-1 \alpha)$, at $30 \mathrm{ng} / \mathrm{mL}$, augmented the passage of PBMC. Stimulation of fibroblasts with TNF- $\alpha$ increased the number of migrated leukocytes by $50 \%$ (Fig. 4D). Co-stimulation of fibroblasts with TNF- $\alpha$ and granulocytes or PBMC with chemoattractants resulted in additive effects (Fig. 4E and F). Under maximal stimulation, about 6 to $8 \%$ of the applied leukocytes were recovered in the lower well.

To verify whether or not fibroblasts were required for transmigration, fibroblast layer was neutralized by protein fixation with formaldehyde (Fig. 5A). In the absence of fibroblasts and without stimulation, only $1.6 \pm 0.1 \%$ of leukocytes from a total leukocyte preparation was able to cross the filter. In the presence of fibroblasts, a 3-fold increase (5.1 $\pm 1.0 \%)$ in leukocyte migration was observed. After fibroblast fixation, migration went down to basal level (1.2 \pm $0.2 \%)$. We also examined by confocal microscopy whether leukocytes were passing inside or close to leukocytes. As seen in Fig 5B, fibroblasts formed a continuous layer and leukocytes appeared to cross either inside the cytoplasm or at cell-cell junction. These data suggest that fibroblasts act as an active support to permit migration.

To identify which leukocyte type migrated, total leukocytes were deposited on filters with or without a fibroblast layer, and the transmigrated cells were collected and analyzed by flow cytometry (Fig. 5C) in the absence of fibroblasts and chemoattractants, only CD8 ${ }^{+}$ leukocytes were able to cross on the naked filters. However, when fibroblasts were seeded on the filter, the migration of neutrophils and B lymphocytes was favored. Whatever the chemoattractant put in the lower well (Fig. 5D), the proportion of neutrophils and B lymphocytes increased by 3- to 4 -fold compared to their proportion in the initial leukocyte population. It is noteworthy that very few $\mathrm{T}$ cells migrated, whatever the conditions applied. We also attempted to activate and expand T lymphocytes with CD3 and CD28 antibodies in the presence of IL-2 
[25] without further improving transmigration (results not shown). NK cell migration increased significantly only in the presence of fMLP and SDF- $\alpha$. When cardiac fibroblasts were replaced by human skin fibroblasts on the membranes, we obtained essentially similar results: only neutrophils and B lymphocytes were able to cross the fibroblast barriers (data not shown). Altogether, these results of Fig. 5 indicate that the fibroblast layer functioned as active filters, allowing the selective passage of neutrophils and B lymphocytes.

\section{Inhibition of fibroblast-leukocyte interactions}

To examine which receptors are involved in the interactions of leukocytes with fibroblasts, different cocktails of antibodies were added to the medium when both cell types were incubated in suspension. The proportion of $\mathrm{DDAO}^{+} \mathrm{OG}^{+}$fibroblasts was then measured by flow cytometry. As depicted in Fig. 6A-E, blocking antibodies against CD18, CD11a, CD11b, CD11c and ICAM-1 potently inhibited the interactions between neutrophils and fibroblasts, whereas antibodies against CD49d and VCAM-1 had no significant effect. With B lymphocytes, a different pattern was obtained. Antibodies against CD49d/VCAM contributed more than CD18/CD11/ICAM antibodies. When antibodies were added during transmigration in cell inserts, similar inhibition of migration was observed (Fig. 6D and E).

Attempts to block TNF- $\alpha$ - and PMA-stimulated interactions with $250 \mu \mathrm{g} / \mathrm{mL}$ hyaluronidan, a CD44 ligand, with $250 \mu \mathrm{g} / \mathrm{mL}$ fucoidan, a selectin-binding polysaccharide, or with $6 \mu$ g recombinant thy-1 (CD 90), were unsuccessful (results not shown).

To confirm the surface expression of ICAM-1 and VCAM-1 on the fibroblasts, flow cytometry was performed. As revealed in Fig. 6F and G, both adhesion receptors were detected. TNF- $\alpha$ stimulation increased by 2 - to -3 -fold their expression. In addition, cell extracts were 
submitted to Western blotting after overnight TNF- $\alpha$ stimulation. Specific bands of 90 and 100 $\mathrm{kDa}$, respectively, were detected confirming that stimulation of fibroblasts with TNF- $\alpha$ evoked a 3- to 5-fold increase in both bands (normalized to GAPDH) (results not shown). These results are in accordance with a previous report [26]. On the other hand, stimulation of granulocytes with PMA augmented the presence of CD11b and CD11c at the surface of the cells, whereas CD11a, CD11b, and CD18 were increased on PBMC (data not shown), as it has been reported [27]. Because PMA-stimulation was started after leukocytes were deposited on fibroblasts, the possibility exists that this agent also affected directly fibroblast ICAM-1 expression [8].

\section{Migration of leukocytes by a transcellular route}

According to the literature, leukocytes can cross an endothelial layer in 2 ways: by a paracellular route, between adjacent cells, or via a transcellular route, through the cell cytoplasm. The former mechanism is reported to be favored [1]. We thus undertook confocal microscopy to determine whether or not leukocytes crossed the fibroblasts by a paracellular or a transcellular route. For this purpose, cell-cell junctions were visualized by cadherin immunolocalization (Fig. 7). As compared to epithelial and endothelial cells, fibroblast intercellular adherens junctions have a more dotted and dispersed appearance [24]. PBMC and granulocytes appeared to be engulfed far away from cadherin-positive junctions (Fig. 7A and B). Fig. 7C discloses a migration hole close to the cell-cell junctions. We, therefore, measured the distance between the migration holes and the cell-cell junctions, applying the criteria of Carman et al. $[28,29]$ who considered that migration cups should be at a distance greater than $1 \mu \mathrm{m}$ from the junctions to be classified as transcellular. More than 68 and 73\% of internalized PBMC (Fig. 7D) and neutrophils (Fig 7E), respectively, were at a distance greater than $1 \mu \mathrm{m}$ from the cadherin edge. In addition, we 
measured the distance between the migration holes and the fibroblast nucleus based on the assumption that the farther were the migration holes from the membrane the closer they should be from the nucleus. More than 52 and $62 \%$ of migration holes of the PBMC and granulocytes, respectively, were at a distance less than $3 \mu \mathrm{m}$ from the nucleus.

A recent study by Nieminen et al. [30] demonstrated the active involvement of intermediate filaments in leukocyte migration through endothelial cells by the transcellular route. We, therefore, undertook confocal microscopy to ascertain whether or not the migration holes in fibroblasts were associated with vimentin filaments. As seen in Fig. 8, the migration holes of PBMC and granulocytes were nested in densely-packed vimentin filaments, whereas microtubules (tubulin) did not appear to present a densely-packed distribution as vimentin. Fibroblasts myofilaments (actin) did not appear to be linked to the migration holes even though PBMC myofilaments were visible (Fig. 8B and D). 


\section{Discussion}

Our initial observations showed that leukocytes adhered to the fibroblasts. This caused the leukocytes, particularly neutrophils and B lymphocytes, to be engulfed by fibroblasts. In fact, this engulfment appears to represent the crossing by a transcellular route of leukocytes through fibroblasts. Their passage appeared to be mostly dependent on the adhesion molecules ICAM$1 / \beta 2$ integrin and VCAM-1/ $\alpha 4$ integrin. Clearly, our study showed, for the first time, that there are strong cell-in-cell interactions between leukocytes and fibroblasts.

The literature contains several descriptions of cell-cell associations as well as cell-in-cell interactions between leukocytes and fibroblasts. Adherence of leukocytes to fibroblasts has been documented for B [5] and T lymphocytes [7,10,14,15,31] and neutrophils [8,11]. Indeed, our results indicate that all leukocyte types were able to bind cultured fibroblasts. However, neutrophils, B lymphocytes and $\mathrm{CD}^{-} \mathrm{CD}^{+}$cells represented the largest proportion of EGTAeluted cells, compared to unbound cells, suggesting greater adhesiveness to fibroblasts.

A singular phenomenon was encountered when leukocytes adhered to the fibroblasts: portions of leukocytes were embedded in the cytoplasm of the fibroblasts. Further analysis by flow cytometry, confocal and electron microscopy of the embedded leukocytes demonstrated that they could be completely engulfed by the fibroblasts. This phenomenon is, therefore, reminiscent of cell-in-cell interactions, as reviewed recently by Overholtzer and Brugge [32]. The engulfment of lymphocytes by non-phagocitic cells, observed several decades ago, was called emperipolesis [33-36]. In the Rosai-Dorfman disease, histological examination of the lymph nodes revealed that lymphocytes are internalized by histiocytes [37,38]. In addition, another cellular phenomenon, called pseudoemperipolesis, has been described in which lymphoma cells have physical interaction and migrated beneath adherent bone marrow stromal cells $[39,40]$. Whether 
or not emperipolesis and pseudoemperipolesis correspond to a similar event, but taken at different time points, remains to be evaluated. But leukocyte engulfment by fibroblasts and subsequent transmigration may well represent another facet of a similar phenomenon.

Interaction between leukocytes and fibroblasts has been studied further in the context of phagocytosis by non-professional cells [41]. For instance, some reports indicate that apoptotic neutrophils can be engulfed by fibroblasts $[42,43]$. We verified whether or not neutrophils in apoptosis have increased interactions with fibroblasts. Compared to non-apoptotic neutrophils, when $80 \%$ of the neutrophils were in apoptosis, detected by annexin V-FITC-binding, no differences in their interactions with fibroblasts were detected by flow cytometry (data not shown). This result implies that phosphatidylserine and its related receptor, which are important recognition signals in phagocytosis [44], may not be involved in the present cell-in-cell observations.

Considering that leukocytes were engulfed by fibroblasts via a non-apoptotic pathway, we examined whether or not this internalization corresponded to the passage of leukocytes across the fibroblasts. Transmigration assays were then set up, in which a monolayer barrier of fibroblasts was grown on $3-\mu \mathrm{m}$ porous membranes cell inserts. Compared to the absence of fibroblasts, the fibroblast barriers seemed to act as selective filters that allowed only the passage neutrophils and B lymphocytes. A similar situation was observed in the presence of several chemoattractants. The fibroblast layer was thus able to discriminate neutrophils, B lymphocytes, and, under some conditions, $\mathrm{CD} 5^{-} \mathrm{CD} 8^{+}$cells, from other lymphocytes. Stimulation of fibroblasts by TNF- $\alpha$ and the addition of chemoattractant to the lower well significantly increased the transmigration of neutrophils and B lymphocytes with very little effect on T lymphocytes. In general, the fibroblasts were non-permissive to T lymphocytes whichever the chemoattractant 
was tested. The group of Issekutz $[23,45,46]$ and Kahler et al. [47] already reported the passage of neutrophils through a lung fibroblast barrier, but none of these studies described the passage of B lymphocytes. Although fibroblasts do not form tight barrier as represented by endothelium, they can, however, constitute cellular networks in fibrous connective tissues through interconnections via N-cadherin [24].

In accordance with our initial results (Fig. 1A) and with others [15,48,49], T lymphocytes could adhere to fibroblasts. But, the failure of naïve or activated $\mathrm{T}$ cells to cross the fibroblast layer, whatever the conditions used, is perplexing. Still, these cells expressed the appropriate adhesion molecules $\beta 2$ integrins as well as $\alpha 4$ integrin. Interestingly, Bradfield et al. [50] found that $\mathrm{CD} 4^{+} \mathrm{CD} 8^{+} \mathrm{T}$ lymphocytes were able to migrate beneath rheumatoid fibroblast-like synoviocytes in a SDF-1 $\alpha$-dependent manner, but with little or no efficiency on normal fibroblast-like synoviocytes, mouse lung fibroblasts and human dermal fibroblasts. This information suggests that the expression of a specific unidentified receptor, different from VCAM-1, on fibroblasts is required to allow selective transmigration of T cells.

As exemplified by endothelial cells, neutrophil and B lymphocyte transmigration can occur either by a paracellular or a transcellular route, although the paracellular route seems to be favored [51]. Examination of the distance between the migration cups and the cadherin adherens junctions is an index of the paracellular route. Our results indicate that the majority of leukocytes (either neutrophils or PBMC) transmigrated at a distance greater than $1 \mu \mathrm{m}$ from the membrane, suggesting a transcellular route. In addition, the transmigration holes should also be closer to the nucleus. We observed a larger number of events in which the migration holes were adjacent to the nucleus.

We also examined the contribution of cytoskeletal proteins to leukocyte migration in the 
fibroblasts. Vimentin filaments completely surrounded the migration holes, whereas intermediate filaments and myofilaments did not show very strong interactions with the holes. This is in agreement with the work of Nieminen et al. [30] who demonstrated that intermediate filaments contribute to leukocyte adhesion and migration by a transcellular route in endothelial cells. A dynamic role of intermediate filaments during transmigration is thus foreseen in a cell type different from endothelial cells, the fibroblasts. However, the presence of vimentin around the holes did not exclude the contribution of small actin fibers in the engulfment process.

Using different cocktails of blocking antibodies, we showed by 2 different experimental assays, that the interactions between leukocytes and fibroblasts were dependent on the integrins. Almost complete inhibition of interactions was obtained for B lymphocytes, indicating that ICAM- 1 and VCAM- 1 and their related receptors, $\beta 2$ integrin and $\alpha 4$ integrin, were involved in that process. In the case of neutrophils, VCAM-1/a4 integrin partner did not appear to play a significant role. Only exposure to antibodies against ICAM/ $\beta 2$ integrin reached significant inhibition. Our data are in accordance with some publications on interactions between leukocytes and fibroblasts $[7,8,52,53]$, but not with others which found the involvement of CD44 [15], CD90 [51] or carbohydrate-binding receptors [54]. In addition, ICAM-1 and VCAM-1 were detected by flow cytometry and Western blotting on cardiac fibroblasts and their expression increased significantly after stimulation with TNF- $\alpha$. The presence of CD11 sub-units was also augmented following leukocyte stimulation by PMA. These results explain, thus, the observed additive effects of TNF- $\alpha$ and PMA

Overall, our results demonstrate that leukocytes are able to cross fibroblasts mainly by a transcellular route via conventional receptors that have already been described for their transmigration across endothelial cells [1]. However, leukocyte behavior on fibroblasts appears 
to differ from that on endothelial cells in a few aspects. First, the fibroblasts allow the passage of not only neutrophils, but also B lymphocytes, and are relatively impermeable to T cells. Secondly, leukocytes that cross the fibroblasts appear to prefer a transcellular route. In comparison, between 5 to $60 \%$ of them migrate in this way on endothelial cells according to the literature [55]. Is this difference related to the cell type itself or to physical constraints? For instance, confluent endothelial cells in culture are closely packed side-by-side with cells having an hexagonal shape with a radius (r) of 5 to $20 \mu \mathrm{m}$ (cell surface area $\left(2.598 \mathrm{r}^{2}\right)$ of 65 to 1040 $\mu \mathrm{m}^{2}$ ) [56,57].When a leukocyte (diameter 7 to $20 \mu \mathrm{m}$, cell surface area 38 to $314 \mu \mathrm{m}^{2}$ ) attempts to cross a small endothelial cell, there is only limited room between the nucleus and the cell membrane. Consequently, during transmigration, the leukocytes may very often be close to the cell junctions. On the other hand, cultured fibroblasts are much larger cells (for examples, see Fig. 7 and 8 where they are about 25 to $50 \mu \mathrm{m}$ wide with a cell surface area of 405 to $1960 \mu \mathrm{m}^{2}$ ) and the leukocytes can, thus, easily find their way between the nucleus and the membrane. Cell size can thus partially explain why fibroblasts present a higher proportion of cells migrating through the transcellular route. In our opinion, cell size is a factor that has been underestimated in studies concerning how the leucocytes make their way during transmigration. However, this does not exclude the fact that endothelial cells and fibroblasts can express the same receptors at different levels and locations or via different adhesion molecules that have been shown to be implicated in the paracellular route, such as PECAM-1 or JAM [1]. That leukocytes are also highly flexible cells during migration must be taken into account.

In summary, fibroblasts have the capacity to act as selective filters that allow the transcellular passage of neutrophils and B lymphocytes through the participation of the ICAM1/ß2 integrin and VCAM-1/a4 integrin. Although we have not examined whether cellular 
transmigration of leukocytes on fibroblasts can occur in in vivo situations, literature reports examples of disease-associated emperipolesis indicating that such cellular phenomenon can be detected in tissues $[37,58,59]$. How this passage is important in the context of leukocyte infiltration remains to be determined. But, we can speculate that it may influence inflammation at different levels either by facilitating the entering of leukocytes inside connective tissue or by affecting the behavior of both fibroblasts and leukocytes. For instances, cell-cell contacts between different leukocyte types and fibroblasts have been reported to increase chemokine secretion [12,60], fibroblast proliferation [52], neutrophil viability [61], or to activate T lymphocytes [62]. It is not know for the moment whether transmigration itself can induce outcomes that are different from those observed after cell-cell contact alone. 


\section{Acknowledgments}

This work was supported by grants from the Canadian Institutes of Health Research and the Natural Sciences and Engineering Research Council to G.T. The authors thank Éric Massicotte, Martine Dupuis and Dominic Filion for their excellent technical assistance. 


\section{References}

[1] K.Ley, C.Laudanna, M.I.Cybulsky, S.Nourshargh, Getting to the site of inflammation: the leukocyte adhesion cascade updated, Nat.Rev.Immunol. 7 (2007) 678-689.

[2] R.J.McAnulty, Fibroblasts and myofibroblasts: their source, function and role in disease, Int.J.Biochem.Cell Biol. 39 (2007) 666-671.

[3] S.P.Atamas, Complex cytokine regulation of tissue fibrosis, Life Sci. 72 (2002) 631-643.

[4] M.L.Lupher, Jr., W.M.Gallatin, Regulation of fibrosis by the immune system, Adv.Immunol. 89 (2006) 245-288.

[5] D.Abraham, H.Muir, I.Olsen, Adhesion of T and B lymphocytes to fibroblasts in tissue culture, Immunology 65 (1988) 385-392.

[6] M.Artuc, U.M.Steckelings, B.M.Henz, Mast cell-fibroblast interactions: human mast cells as source and inducers of fibroblast and epithelial growth factors, J.Invest.Dermatol. 118 (2002) 391-395.

[7] C.Cabanas, N.Hogg, Lymphocyte-fibroblast adhesion. A useful model for analysis of the interaction of the leucocyte integrin LFA-1 with ICAM-1, FEBS Lett. 292 (1991) 284-288. 
[8] A.L.Giuliani, S.Spisani, T.Cavalletti, E.Reali, L.Melchiorri, L.Ferrari, F.Lanza, S.Traniello, Fibroblasts increase adhesion to neutrophils after stimulation with phorbol ester and cytokines, Cell Immunol. 149 (1993) 208-222.

[9] R.Gonzalez-Amaro, D.Arcon-Segovia, J.Alcocer-Varela, L.Diaz de Leon, Y.Rosenstein, Mononuclear cell-fibroblast interactions in scleroderma, Clin.Immunol.Immunopathol. 46 (1988) 412-420.

[10] T.H.Piela, J.H.Korn, Lymphocyte-fibroblast adhesion induced by interferon-gamma, Cell Immunol. 114 (1988) 149-160.

[11] A.Shock, G.J.Laurent, Adhesive interactions between fibroblasts and polymorphonuclear neutrophils in vitro, Eur.J.Cell Biol. 54 (1991) 211-216.

[12] L.Hao, H.Okada, Y.Kanno, T.Inoue, T.Kobayashi, Y.Watanabe, F.Strutz, G.A.Muller, H.Suzuki, Direct contact between human peripheral blood mononuclear cells and renal fibroblasts facilitates the expression of monocyte chemoattractant protein-1, Am.J.Nephrol. 23 (2003) 208-213.

[13] C.M.Hogaboam, R.E.Smith, S.L.Kunkel, Dynamic interactions between lung fibroblasts and leukocytes: implications for fibrotic lung disease, Proc.Assoc.Am.Physicians 110 (1998) 313-320. 
[14] H.Meng, M.J.Marchese, J.A.Garlick, A.Jelaska, J.H.Korn, J.Gailit, R.A.Clark, B.L.Gruber, Mast cells induce T-cell adhesion to human fibroblasts by regulating intercellular adhesion molecule-1 and vascular cell adhesion molecule-1 expression, J.Invest.Dermatol. 105 (1995) 789-796.

[15] S.Murakami, Y.Shimabukuro, T.Saho, E.Hino, D.Kasai, T.Hashikawa, H.Hirano, H.Okada, Immunoregulatory roles of adhesive interactions between lymphocytes and gingival fibroblasts, J.Periodontal Res. 32 (1997) 110-114.

[16] N.G.Frangogiannis, The immune system and cardiac repair, Pharmacol.Res. 58 (2008) 88111.

[17] G.Thibault, M.J.Lacombe, L.M.Schnapp, A.Lacasse, F.Bouzeghrane, G.Lapalme, Upregulation of $\alpha_{8} \beta_{1}$-integrin in cardiac fibroblasts by angiotensin II and transforming growth factor- $\beta 1$, Am.J.Physiol. 281 (2001) C1457-C1467.

[18] F.Hudon-David, F.Bouzeghrane, P.Couture, G.Thibault, Thy-1 expression by cardiac fibroblasts: lack of association with myofibroblast contractile markers, J.Mol.Cell.Cardiol. 42 (2007) 991-1000.

[19] T.Sugawara, M.Miyamoto, S.Takayama, M.Kato, Separation of neutrophils from blood in human and laboratory animals and comparison of the chemotaxis, J.Pharmacol.Toxicol.Methods 33 (1995) 91-100. 
[20] G.R.Woollett, A.N.Barclay, M.Puklavec, A.F.Williams, Molecular and antigenic heterogeneity of the rat leukocyte-common antigen from thymocytes and $\mathrm{T}$ and $\mathrm{B}$ lymphocytes, Eur.J.Immunol. 15 (1985) 168-173.

[21] T.K.van den Berg, M.J.Puklavec, A.N.Barclay, C.D.Dijkstra, Monoclonal antibodies against rat leukocyte surface antigens, Immunol.Rev. 184 (2001) 109-116.

[22] A.H.Miller, R.L.Spencer, J.Hassett, C.Kim, R.Rhee, D.Ciurea, F.Dhabhar, B.McEwen, M.Stein, Effects of selective type I and II adrenal steroid agonists on immune cell distribution, Endocrinology 135 (1994) 1934-1944.

[23] W.Morzycki, A.C.Issekutz, Tumour necrosis factor-alpha but not interleukin-1 induces polymorphonuclear leucocyte migration through fibroblast layers by a fibroblast-dependent mechanism, Immunology 74 (1991) 107-113.

[24] T.Y.El Sayegh, A.Kapus, C.A.McCulloch, Beyond the epithelium: cadherin function in fibrous connective tissues, FEBS Lett. 581 (2007) 167-174.

[25] D.Davidson, B.Schraven, A.Veillette, PAG-associated FynT regulates calcium signaling and promotes anergy in T lymphocytes, Mol.Cell Biol. 27 (2007) 1960-1973.

[26] R.Kacimi, J.S.Karliner, F.Koudssi, C.S.Long, Expression and regulation of adhesion molecules in cardiac cells by cytokines: response to acute hypoxia, Circ.Res. 82 (1998) 576-586. 
[27] M.Patarroyo, J.Prieto, J.Rincon, T.Timonen, C.Lundberg, L.Lindbom, B.Asjo, C.G.Gahmberg, Leukocyte-cell adhesion: a molecular process fundamental in leukocyte physiology, Immunol.Rev. 114 (1990) 67-108.

[28] C.V.Carman, T.A.Springer, A transmigratory cup in leukocyte diapedesis both through individual vascular endothelial cells and between them, J.Cell Biol. 167 (2004) 377-388.

[29] C.V.Carman, P.T.Sage, T.E.Sciuto, M.A.de la Fuente, R.S.Geha, H.D.Ochs, H.F.Dvorak, A.M.Dvorak, T.A.Springer, Transcellular diapedesis is initiated by invasive podosomes, Immunity 26 (2007) 784-797.

[30] M.Nieminen, T.Henttinen, M.Merinen, F.Marttila-Ichihara, J.E.Eriksson, S.Jalkanen, Vimentin function in lymphocyte adhesion and transcellular migration, Nat.Cell Biol. 8 (2006) 156-162.

[31] B.White, J.H.Korn, T.H.Piela-Smith, Preferential adherence of human gamma delta, CD8+, and memory T cells to fibroblasts, J.Immunol. 152 (1994) 4912-4918.

[32] M.Overholtzer, J.S.Brugge, The cell biology of cell-in-cell structures, Nat.Rev.Mol.Cell Biol. 9 (2008) 796-809.

[33] R.J.Pulvertaft, Cellular associations in normal and abnormal lymphocytes, Proc.R.Soc.Med. 52 (1959) 315-322. 
[34] H.L.Ioachim, Emperipolesis of lymphoid cells in mixed cultures, Lab.Invest. 14 (1965) 1784-1794.

[35] J.G.Sinkovics, C.C.Shullenberger, C.D.Howe, Cell destruction by lymphocytes, Lancet 287 (1966) 1215-1216.

[36] J.G.Humble, W.H.Jayne, R.J.Pulvertaft, Biological interaction between lymphocytes and other cells, Br.J.Haematol. 2 (1956) 283-294.

[37] A.Carbone, A.Passannante, A.Gloghini, K.O.Devaney, A.Rinaldo, A.Ferlito, Review of sinus histiocytosis with massive lymphadenopathy (Rosai-Dorfman disease) of head and neck, Ann.Otol.Rhinol.Laryngol. 108 (1999) 1095-1104.

[38] L.Galicier, C.Fieschi, V.Meignin, J.P.Clauvel, E.Oksenhendler, [Rosai-Dorfman disease], Presse Med. 36 (2007) 1669-1675.

[39] K.Miyake, Y.Hasunuma, H.Yagita, M.Kimoto, Requirement for VLA-4 and VLA-5 integrins in lymphoma cells binding to and migration beneath stromal cells in culture, J.Cell Biol. 119 (1992) 653-662.

[40] J.A.Burger, M.Burger, T.J.Kipps, Chronic lymphocytic leukemia B cells express functional CXCR4 chemokine receptors that mediate spontaneous migration beneath bone marrow stromal cells, Blood 94 (1999) 3658-3667. 
[41] M.Rabinovitch, Professional and non-professional phagocytes: an introduction, Trends Cell Biol. 5 (1995) 85-87.

[42] S.E.Hall, J.S.Savill, P.M.Henson, C.Haslett, Apoptotic neutrophils are phagocytosed by fibroblasts with participation of the fibroblast vitronectin receptor and involvement of a mannose/fucose-specific lectin, J.Immunol. 153 (1994) 3218-3227.

[43] V.A.Fadok, A.de Cathelineau, D.L.Daleke, P.M.Henson, D.L.Bratton, Loss of phospholipid asymmetry and surface exposure of phosphatidylserine is required for phagocytosis of apoptotic cells by macrophages and fibroblasts, J.Biol.Chem. 276 (2001) 1071-1077.

[44] Y.Wu, N.Tibrewal, R.B.Birge, Phosphatidylserine recognition by phagocytes: a view to a kill, Trends Cell Biol. 16 (2006) 189-197.

[45] J.X.Gao, A.C.Issekutz, Mac-1 (CD11b/CD18) is the predominant beta 2 (CD18) integrin mediating human neutrophil migration through synovial and dermal fibroblast barriers, Immunology 88 (1996) 463-470.

[46] X.Z.Shang, A.C.Issekutz, Beta 2 (CD18) and beta 1 (CD29) integrin mechanisms in migration of human polymorphonuclear leucocytes and monocytes through lung fibroblast barriers: shared and distinct mechanisms, Immunology 92 (1997) 527-535. 
[47] C.M.Kahler, A.Pischel, G.Kaufmann, C.J.Wiedermann, Influence of neuropeptides on neutrophil adhesion and transmigration through a lung fibroblast barrier in vitro, Exp.Lung Res. 27 (2001) 25-46.

[48] A.Musso, T.P.Condon, G.A.West, M.C.De La, S.A.Strong, A.D.Levine, C.F.Bennett, C.Fiocchi, Regulation of ICAM-1-mediated fibroblast-T cell reciprocal interaction: implications for modulation of gut inflammation, Gastroenterology 117 (1999) 546-556.

[49] J.X.Gao, A.C.Issekutz, Expression of VCAM-1 and VLA-4 dependent T-lymphocyte adhesion to dermal fibroblasts stimulated with proinflammatory cytokines, Immunology 89 (1996) 375-383.

[50] P.F.Bradfield, N.Amft, E.Vernon-Wilson, A.E.Exley, G.Parsonage, G.E.Rainger, G.B.Nash, A.M.Thomas, D.L.Simmons, M.Salmon, C.D.Buckley, Rheumatoid fibroblast-like synoviocytes overexpress the chemokine stromal cell-derived factor 1 (CXCL12), which supports distinct patterns and rates of $\mathrm{CD} 4+$ and $\mathrm{CD} 8+\mathrm{T}$ cell migration within synovial tissue, Arthritis Rheum. 48 (2003) 2472-2482.

[51] T.A.Rege, J.S.Hagood, Thy-1 as a regulator of cell-cell and cell-matrix interactions in axon regeneration, apoptosis, adhesion, migration, cancer, and fibrosis, FASEB J. 20 (2006) 1045-1054. 
[52] A.Shock, K.F.Rabe, G.Dent, R.C.Chambers, A.J.Gray, K.F.Chung, P.J.Barnes, G.J.Laurent, Eosinophils adhere to and stimulate replication of lung fibroblasts 'in vitro', Clin.Exp.Immunol. 86 (1991) 185-190.

[53] T.H.Piela, J.H.Korn, ICAM-1-dependent fibroblast-lymphocyte adhesion: discordance between surface expression and function of ICAM-1, Cell Immunol. 129 (1990) 125-137.

[54] D.Abraham, G.Bou-Gharios, H.Muir, I.Olsen, Adhesion of lymphoid cells to fibroblasts in tissue culture, Cell Immunol. 122 (1989) 33-47.

[55] C.V.Carman, T.A.Springer, Trans-cellular migration: cell-cell contacts get intimate, Curr.Opin.Cell Biol. 20 (2008) 533-540.

[56] K.Hashimoto, N.Kataoka, E.Nakamura, H.Asahara, Y.Ogasawara, K.Tsujioka, F.Kajiya, Direct observation and quantitative analysis of spatiotemporal dynamics of individual living monocytes during transendothelial migration, Atherosclerosis 177 (2004) 19-27.

[57] J.A.Madri, B.M.Pratt, J.Yannariello-Brown, Matrix-driven cell size change modulates aortic endothelial cell proliferation and sheet migration, Am.J.Pathol. 132 (1988) 18-27.

[58] T.Ochi, H.Yoshikawa, T.Toyosaki-Maeda, P.E.Lipsky, Mesenchymal stromal cells. Nurselike cells reside in the synovial tissue and bone marrow in rheumatoid arthritis, Arthritis Res.Ther. 9 (2007) 201. 
[59] A.Tefferi, Pathogenesis of myelofibrosis with myeloid metaplasia, J.Clin.Oncol. 23 (2005) $8520-8530$.

[60] R.E.Smith, C.M.Hogaboam, R.M.Strieter, N.W.Lukacs, S.L.Kunkel, Cell-to-cell and cellto-matrix interactions mediate chemokine expression: an important component of the inflammatory lesion, J.Leukoc.Biol. 62 (1997) 612-619.

[61] C.J.Ling, W.F.Owen, Jr., K.F.Austen, Human fibroblasts maintain the viability and augment the functional response of human neutrophils in culture, J.Clin.Invest 85 (1990) 601-604.

[62] D.Riemann, J.Rontsch, B.Hause, J.Langner, A.Kehlen, Cell-cell contact between lymphocytes and fibroblast-like synoviocytes induces lymphocytic expression of aminopeptidase N/CD13 and results in lymphocytic activation, Adv.Exp.Med.Biol. 477 (2000) 57-66. 
Figure legends

Figure 1. Adhesion of leukocytes on fibroblasts. A. Total leukocyte preparation was deposited on confluent cultured fibroblasts. After 45 minutes, unbound leukocytes were removed and collected. Bound cells were eluted with Hanks' buffered saline solution plus 5 mM EGTA. The proportions of neutrophils (RK-4 $\left.4^{+}\right)$, B lymphocytes $\left(\mathrm{CD} 45 \mathrm{RA}^{+}\right)$, T helper lymphocytes $\left(\mathrm{CD}^{+} \mathrm{CD}^{+}\right)$, $\mathrm{T}$ cytotoxic lymphocytes $\left(\mathrm{CD}^{+} \mathrm{CD}^{+}\right)$, and $\mathrm{NK}$ cells $\left(\mathrm{CD} 5^{-} \mathrm{CD} 8^{+}\right)$cells were then characterized by flow cytometry with specific markers from total, unbound and EGTA-eluted bound cell populations. B to G. DDAO-pre-labeled PBMC (C) or granulocytes (F), which appear in blue, were deposited on Oregon Green-pre-labeled cultured fibroblasts (green, B and E) for 45 minutes. After removing unbound cells and fixation, the cells were examined by confocal microscopy. Several PBMC and granulocytes adhered to fibroblasts (white arrows), whereas many others were engulfed in them (red arrows). H. A 3-dimensional view was reconstituted from a stack of 10 consecutive $0.5 \mu$ m-slices along the $\mathrm{Z}$ axis. The higher magnification reveals that a leukocyte was inserted beneath a fibroblast. $* \mathrm{p} \leq 0.05$ versus the corresponding cell type in the total leukocyte population.

Figure 2. Confocal and electron microscopy of engulfed leukocytes in fibroblasts. A. Oregon Green-pre-labeled PBMC (green) were incubated in suspension with DDAO-pre-labeled fibroblasts (blue) for $1 \mathrm{~h}$. The cells were then analyzed on a MoFlow cell sorter and those that were positive for both tracers (R2) were collected. B to D. $\mathrm{DDAO}^{+} \mathrm{OG}^{+}$cells were deposited on glass slides by Cytospin centrifugation and examined by confocal microscopy. The images show several engulfed PBMC. E. A 3-dimensional view at higher magnification with XY, XZ and YZ views, from a stack of 16 consecutive $0.5 \mu \mathrm{m}$ slices, of an engulfed PBMC. F and G. Electron 
microscopy of engulfed neutrophil (F) and PBMC (G). Nfb, fibroblast nucleus; Nn, neutrophil nucleus; Nm, mononuclear cell nucleus.

Figure 3. Increased cell-cell interactions after TNF- $\alpha$ stimulation of fibroblasts and PMAactivation of leukocytes. A. Representative flow cytometry histograms obtained after incubation of DDAO-labeled fibroblasts with Oregon Green-labeled granulocytes. Fibroblasts were stimulated overnight with $10 \mathrm{ng} / \mathrm{mL}$ TNF- $\alpha$ and leukocytes for 30 minutes with $10^{-8}$ M PMA. B and $\mathrm{C}$. The number of $\mathrm{DDAO}^{+} \mathrm{OG}^{+}$fibroblasts in the upper right quadrant was calculated as percentages of total fibroblasts. Incubation of the leukocytes with PMA and TNF- $\alpha$ stimulation of cardiac fibroblasts (B) or human skin fibroblasts (C) resulted in a significant \% increase of DDAO ${ }^{+} \mathrm{OG}^{+}$fibroblasts. $\mathrm{n}=3 .{ }^{*} \mathrm{p} \leq 0.05$ versus control.

Figure 4. Transmigration of leukocytes on fibroblasts in a modified Boyden chamber. Fibroblasts were seeded on 3- $\mu \mathrm{m}$ pore size filters until confluence. Different factors were tested to obtain optimal transmigration. Oregon Green-labeled leukocytes were used to assess the number of migrated cells under the filters by spectrofluorometry. A. Duration of migration after the deposition of $2 \times 10^{5}$ granulocytes on the fibroblast layer. Representative experiment with $\mathrm{n}=3$. B. Number of granulocytes deposited in the inserts. Representative experiment with $\mathrm{n}=3$. C. Concentration of fMLP applied as a chemoattractant with $6 \times 10^{5}$ granulocytes. Representative experiment with $n=3$. D. TNF- $\alpha$ concentration for fibroblast stimulation with $6 \times 10^{5}$ granulocytes. Representative experiment with $n=3$. E. Optimized transmigration of $6 \times 10^{5}$ granulocytes on a fibroblast layer. Compilation of 4 experiments with $n=3$ for each. $\mathbf{F}$. Optimized transmigration of $6 \times 10^{5}$ PBMC on a fibroblast layer. Compilation of 4 experiments 
with $\mathrm{n}=3$ for each. $* \mathrm{p} \leq 0.05$ versus control.

Figure 5. Fibroblasts act as a selective filter for neutrophils and B lymphocytes. A. A total leukocyte preparation was applied on inserts without fibroblasts, with intact or formaldehydefixed fibroblasts. $n=3{ }^{*} \mathrm{p} \leq 0.05$ versus without fibroblasts. $\dagger \mathrm{p} \leq 0.05$ versus fixed fibroblasts. B. Leukocyte migration on the filter insert was visualized by confocal microscopy. Fibroblasts were loaded with CellTrace Oregon Green (green) and nuclei stained with TO-PRO-3 (blue). Image shows a 3-dimensional view, reconstituted from a stack of 25 consecutive $0.5 \mu \mathrm{m}$-slices along the $\mathrm{Z}$ axis, in which several leukocytes were migrating (designated $\mathrm{M}$ ) or adhered (S) on the fibroblast layer. Several M nuclei are not visible because they are in lower $\mathrm{Z}$ planes. A leukocyte nucleus was also detected crossing the filter (white arrows). C. Leukocytes that migrated under the filters were characterized by flow cytometry with specific markers and indentified as shown in figure 1A. In the absence of fibroblasts on the filters and without chemoattractant, only $\mathrm{T}$ lymphocytes migrated under the filters. In the presence of the fibroblasts and without chemoattractants, selective migration of neutrophils and B cells was observed. D. In the presence of fibroblasts on the filters and with chemoattractants, the transmigration of neutrophils and B lymphocytes, and, in some cases, $\mathrm{CD} 5^{-} \mathrm{CD} 8^{+}$cells, was favored. * $\mathrm{p} \leq 0.05$ versus the corresponding cell type in the total leukocyte population.

Figure 6. Involvement of $\beta 2$ and $\alpha 4$ integrins, ICAM-1 and VCAM-1, in leukocyte transmigration on fibroblasts. A. Binding experiments by flow cytometry of granulocytes with fibroblasts in the absence of antibodies (control) or in the presence of nonspecific mouse $\operatorname{IgG}(21$ $\mu \mathrm{g} / 10^{6}$ leukocytes) or of cocktails of blocking antibodies ( $6 \mu \mathrm{g}$ each $/ 10^{6}$ cells). B. Binding 
experiments, by flow cytometry, of PBMC with fibroblasts in the absence or presence of blocking antibodies. C. Binding experiments, by flow cytometry, of B lymphocytes with fibroblasts in the absence or presence of blocking antibodies. D. Transmigration assays of granulocytes on fibroblasts in the absence or presence of antibodies. E. Transmigration assays of B lymphocytes on fibroblasts in the absence or presence of antibodies. $n=3$ for each experiment. * $\mathrm{p} \leq 0.05$ versus control. F and G. Flow cytometry analysis detected the presence of ICAM-1 and VCAM-1 on control and TNF- $\alpha$ stimulated fibroblasts (bg, non-specific isotype control). $\mathrm{n}=6 .{ }^{*} \mathrm{p} \leq 0.001$ versus control.

Figure 7. Migration of leukocytes in fibroblasts by a transcellular route. DDAO-pre-labeled PBMC or granulocytes (blue) were deposited for 45 minutes on Oregon Green-pre-labeled fibroblasts (green) grown on culture slides. After incubation and the removal of unbound leukocytes, the cells were fixed, and adherens junctions were revealed with an anti-pan-cadherin antibody (red). A. PBMC transmigration on fibroblasts far away from the adherent junctions. B. Granulocyte transmigration on fibroblasts far away from the adherens junctions. C. Granulocyte transmigration on fibroblasts close to the adherens junctions. D. Histograms showing the distance between the migration holes of mononuclear cells and the adherens junctions or nuclei. E. Histograms quantifying the distance between the migration holes of granulocytes and the adherens junctions or nuclei.

Figure 8. The migration holes are surrounded by vimentin filaments. DDAO-pre-labeled PBMC or granulocytes (blue) were deposited for 45 minutes on fibroblasts grown on culture slides. After incubation and the removal of unbound leukocytes, the cells were fixed, and cytoskeletal 
proteins were revealed with anti-tubulin (green) and TRITC-phalloidin (red) or anti-vimentin (green) and TRITC-phalloidin (red). A and C. Granulocytes on fibroblasts. B and D. PBMC on fibroblasts. PBMC contain myofilaments and show, thus, a small rim phalloidin staining around them. 
Figure 1
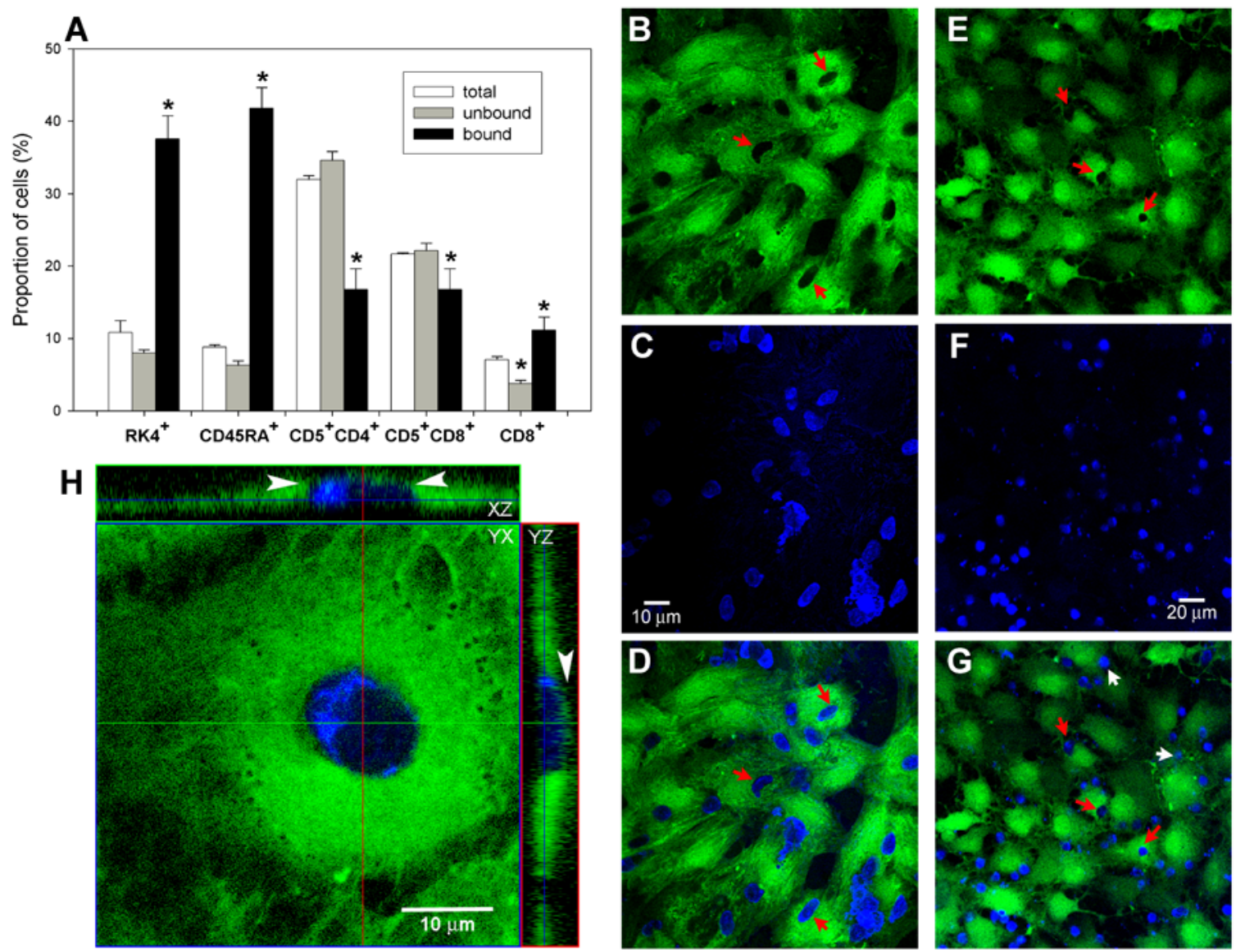
Figure 2
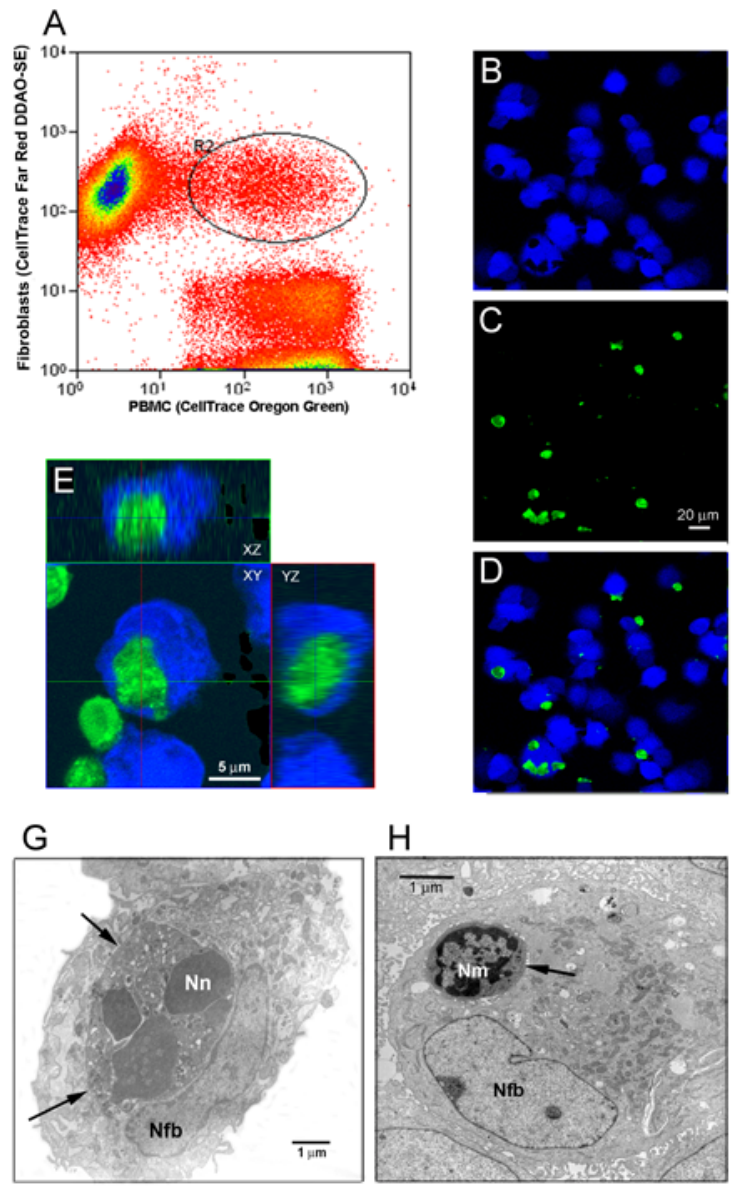
Figure 3

A

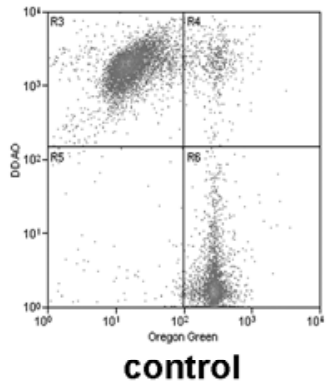

B

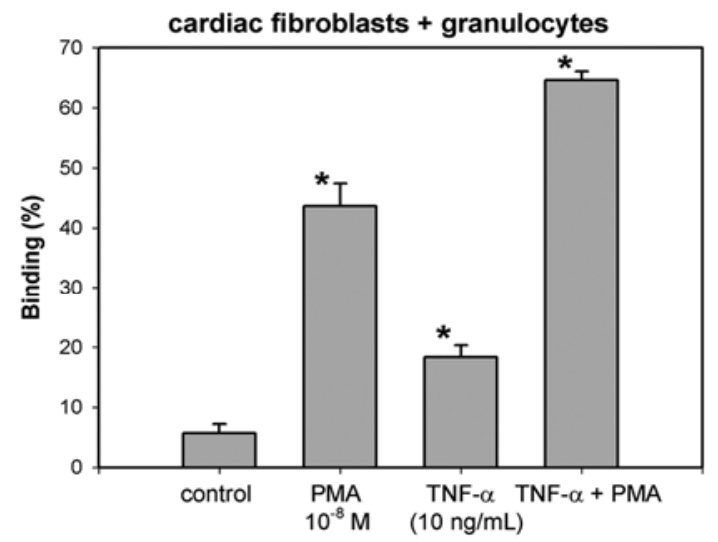

C

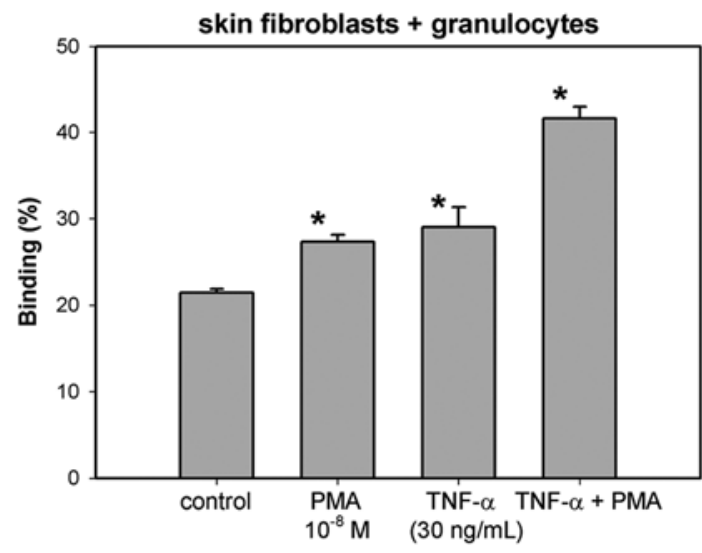

$\left(10^{-8} \mathrm{M}\right)$

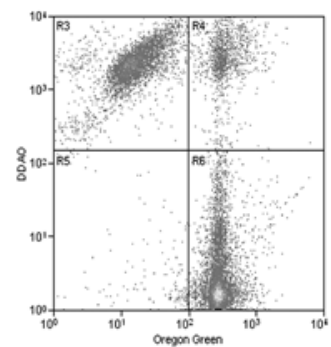

TNF- $\alpha$

(10 ng/mL)

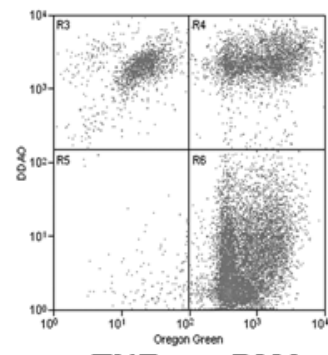

TNF- $\alpha+$ PMA
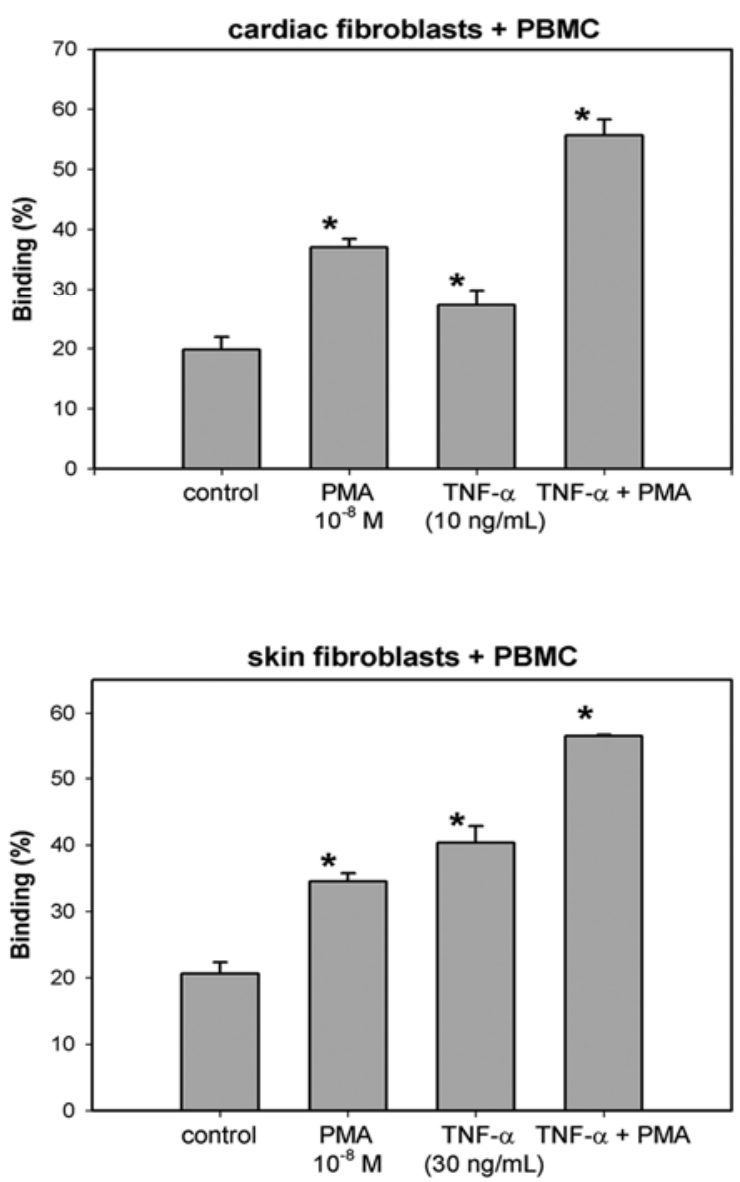
Figure 4
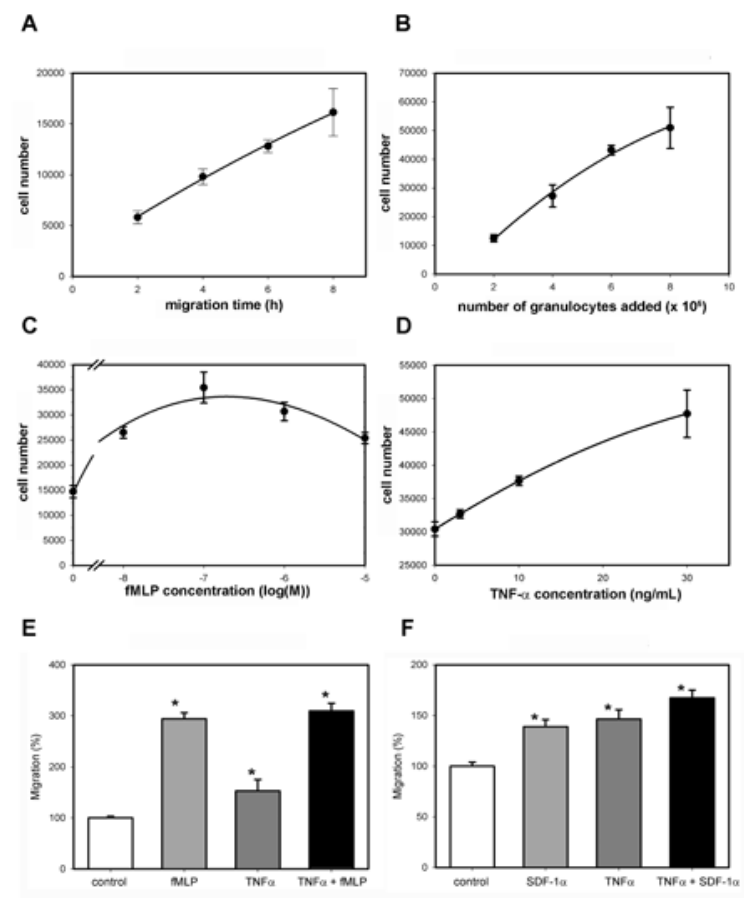
Figure 5

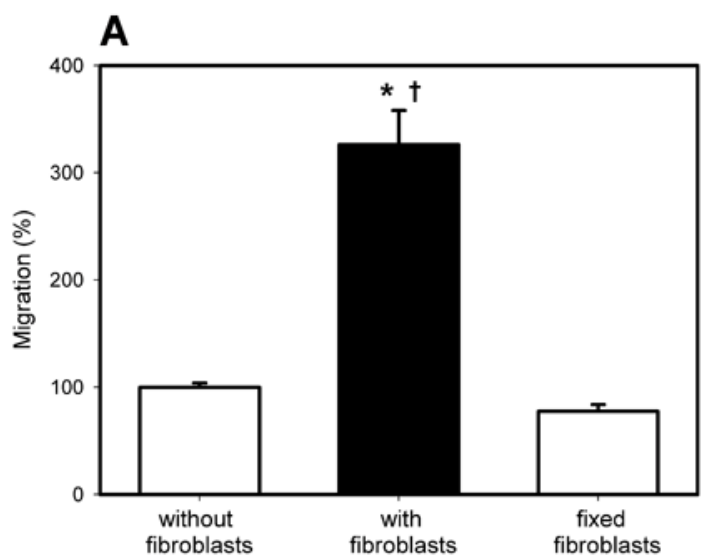

B

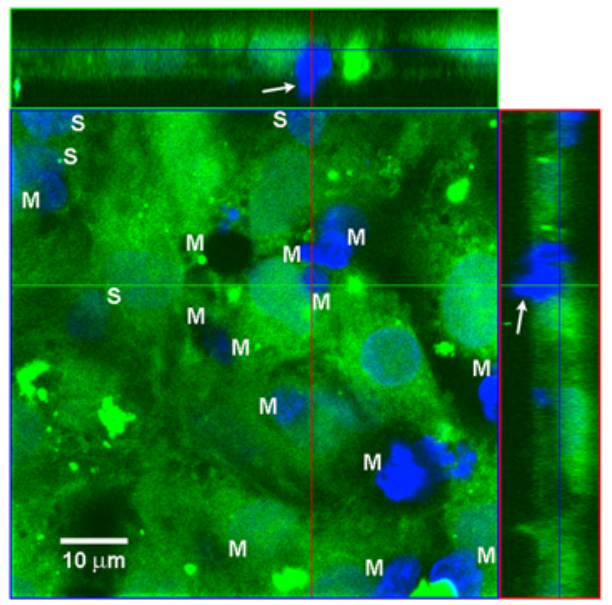

C

D
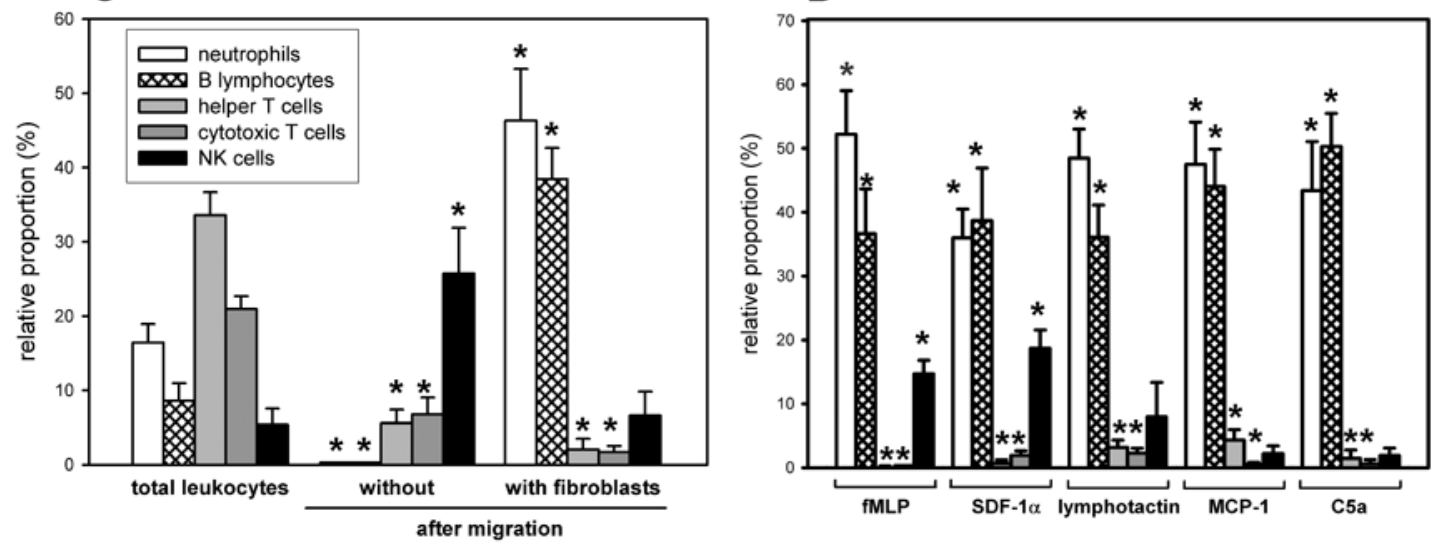
Figure 6
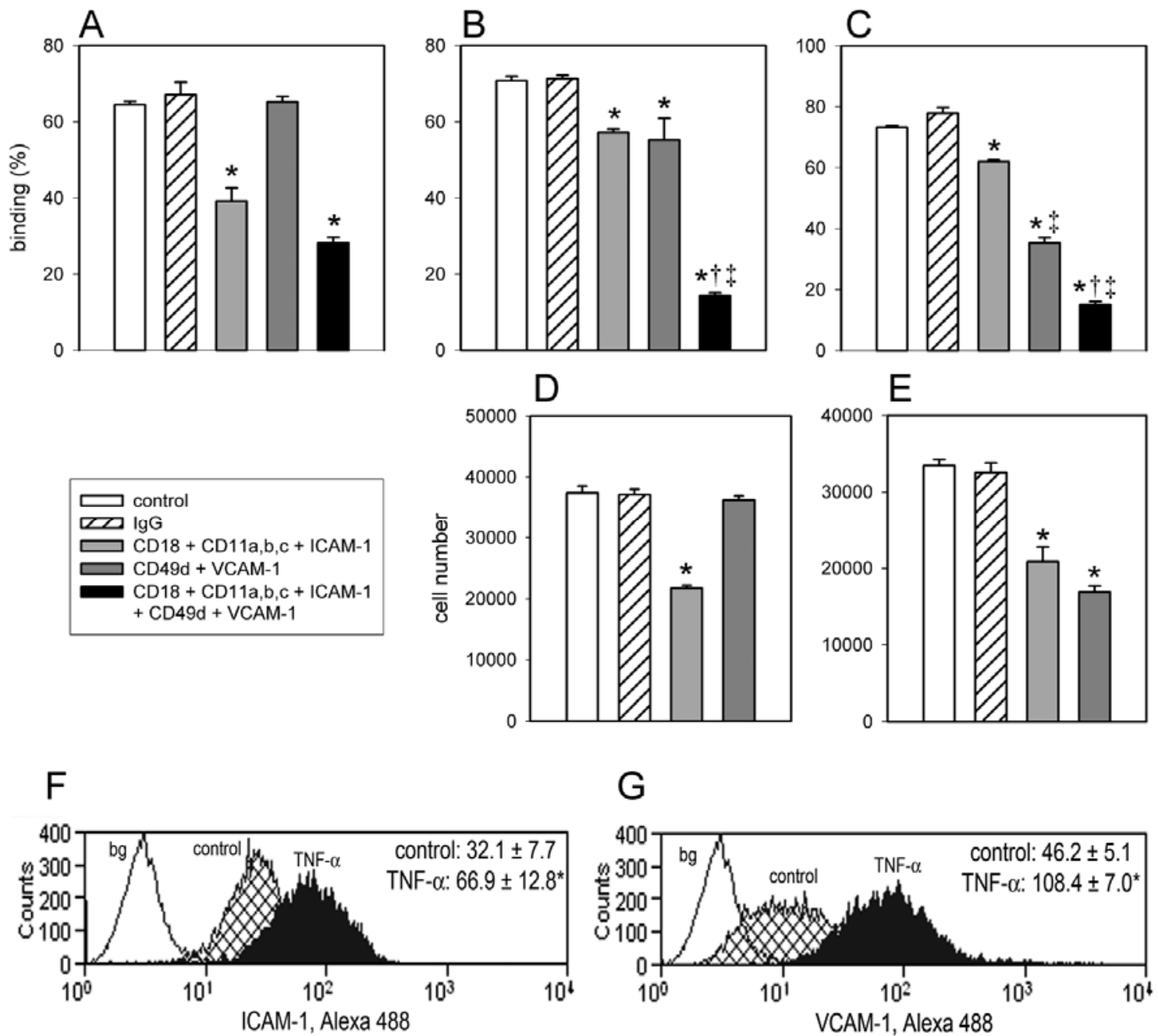
Figure 7
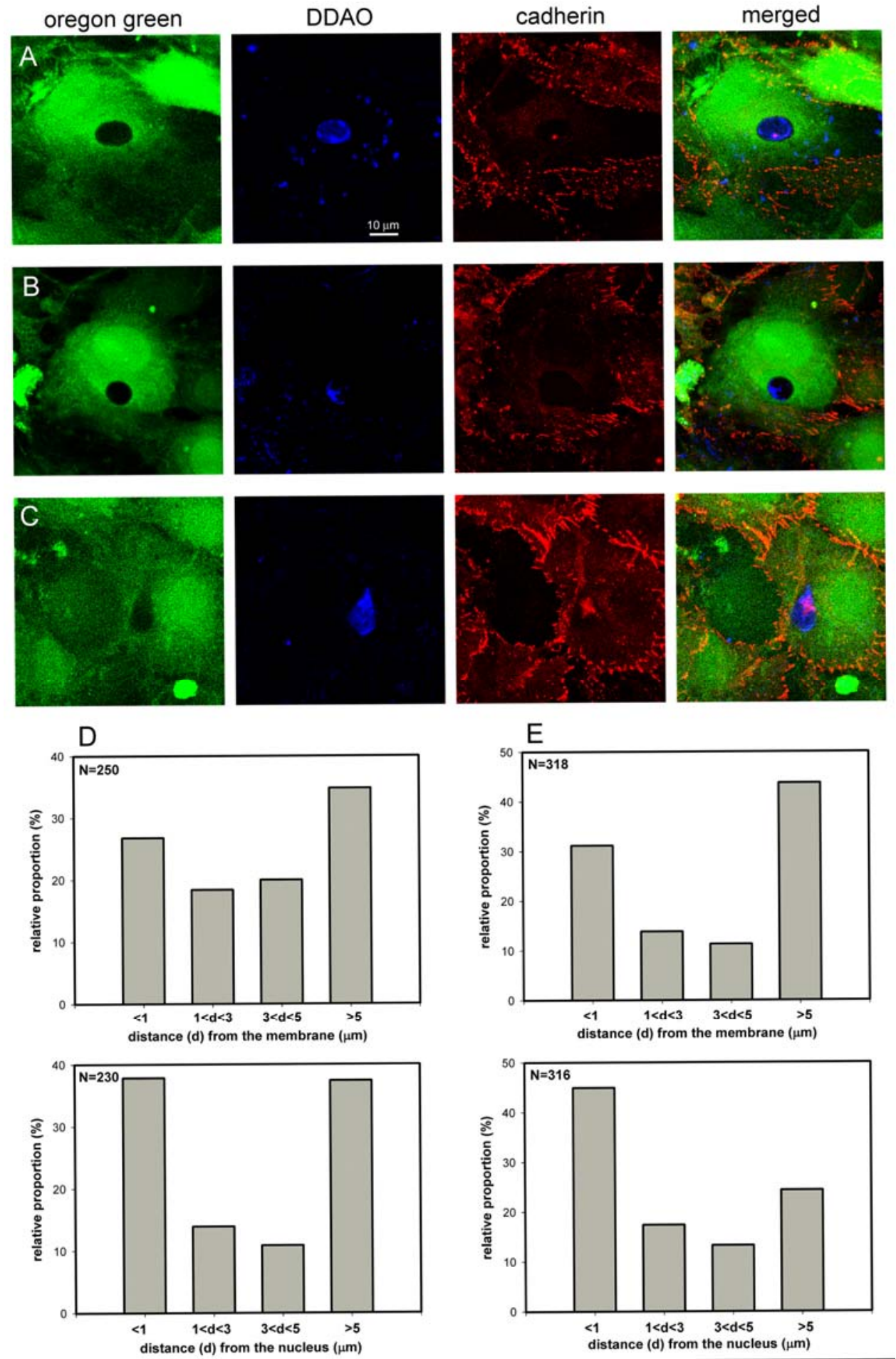
Figure 8
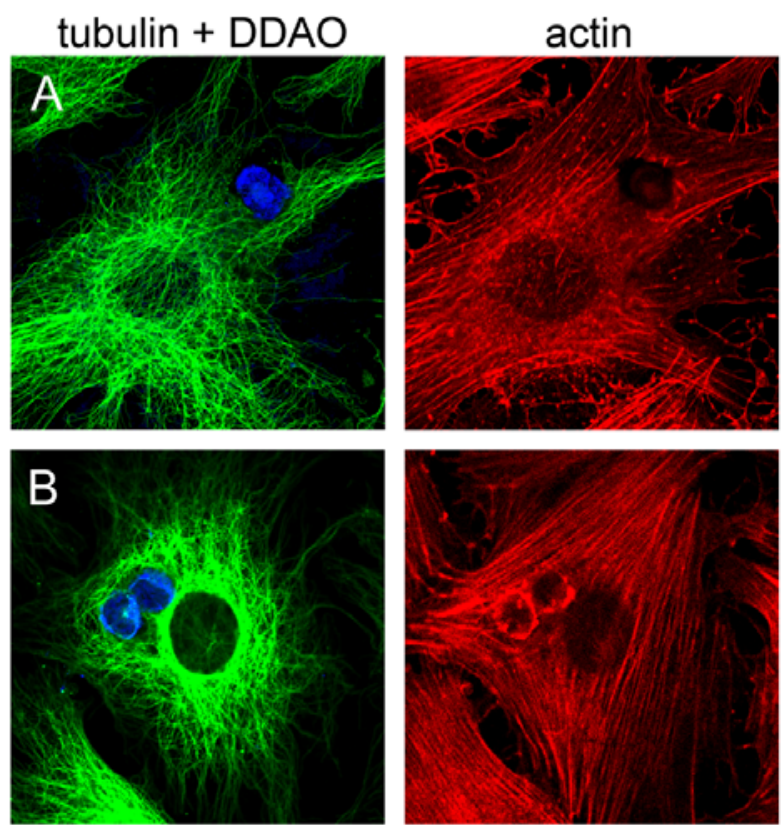

vimentin + DDAO
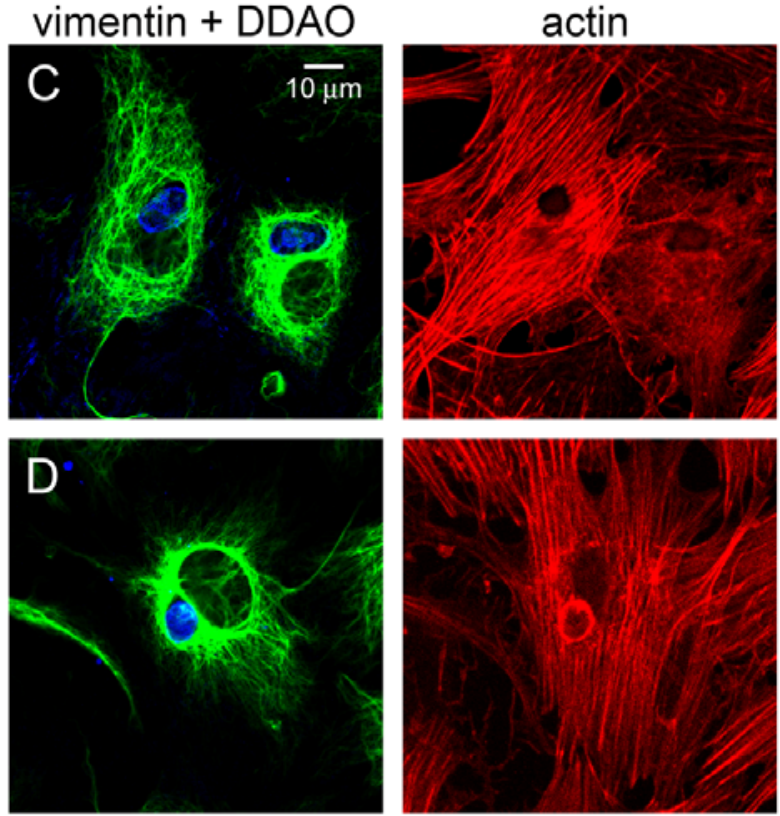